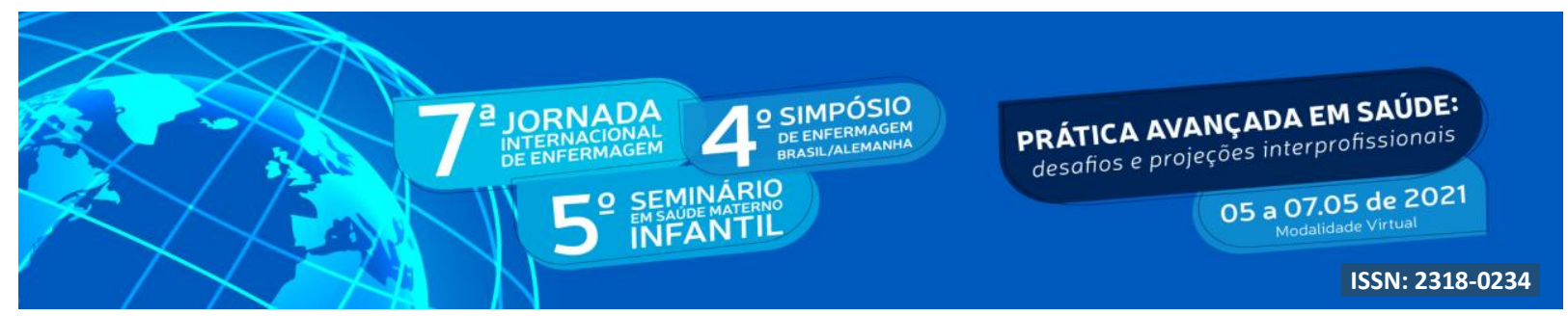

DOI: http://doi.org/10.48195/jie2021-038

\title{
RODA DE CONVERSA ONLINE SOBRE REIKI EM TEMPOS DE PANDEMIA: UM RELATO DE EXPERIÊNCIA
}

\author{
Flávia Camef Dorneles Lenz ${ }^{1}$; Nathália Fortes Schlotfeldt² ${ }^{2}$ Claudete Moreschi³
}

\begin{abstract}
RESUMO
As Práticas Integrativas e Complementares em Saúde constituem um grupo de terapias que não fazem parte dos tratamentos convencionais, assim contribuem por colocar o indivíduo como centro do processo. Ao se aplicar Reiki utiliza-se a energia universal e promove a cura através da ativação emocional e relaxamento, ajudando o corpo na busca de um equilibro proporcionando potencializar os resultados de promoção e reabilitação na vida do indivíduo. Tem-se por objetivo relatar a experiência de acadêmicas que desenvolveram um projeto de ação social em meio a pandemia COVID-19. A prática de Reiki foi realizada por meio de encontro online pela plataforma google meet. O estudo mostrou que mesmo as tecnologias digitais possibilitaram produzir saúde e cuidado impulsionando a busca por um completo bem-estar biopsicossocial durante o cenário vivido.
\end{abstract}

Palavras-chave: Enfermagem; Terapias Complementares; Pandemia.

\begin{abstract}
The Integrative and Complementary Practices in Health former a group of therapies that are not part of the conventional ones, thus contributing by placing the individual as the center of the process. When applying Reiki, universal energy is used and it promotes healing through emotional and relaxing activation, helping the body in the search for a balance providing potential to promote the results of promotion and rehabilitation in the individual's life. It aims to report the experience of academics who develop a social action project in the midst of a COVID-19 pandemic. The practice of Reiki was carried out through an online meeting through the google meet platform. The study revealed that even digital technologies made it possible to produce health and care, driving a search for complete biopsychosocial well-being during the lived scenario.
\end{abstract}

Key Words: Nursing; Complementary Therapies; Pandemic;

\footnotetext{
${ }^{1}$ Estudante do Curso de Enfermagem. Universidade Regional e Integrada do Alto Uruguai e das Missões Campus Santiago. E-mail: flaviacamefd@gmail.com

${ }^{2}$ Estudante do Curso de Enfermagem. Universidade Regional e Integrada do Alto Uruguai e das Missões Campus Santiago. E-mail: nathaliafschlotfeldt@gmail.com

3 Orientador. Enfermeira. Doutora em Ciências: Ambiente e Desenvolvimento. Docente da Universidade Regional e Integrada do Alto Uruguai e das Missões - Campus Santiago. E-mail: clau_moreschi@yahoo.com.br
} 


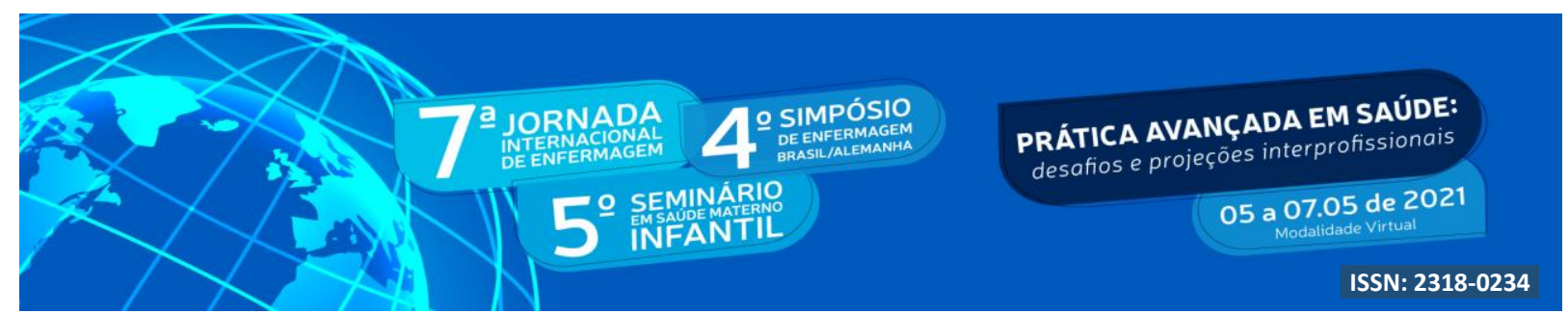

\section{INTRODUÇÃO}

As Práticas Integrativas e Complementares em Saúde (PICS) foram implementadas no Brasil a partir do ano de 2006 por meio da Política Nacional de Práticas Integrativas e Complementares (PNPIC), instituída pela portaria no 971 do Ministério da Saúde (MS) (BRASIL, 2006).

Já no ano de 2017, a portaria nº 849/2017 de 27 de março, conduziu um grande avanço no uso das PICS. Por meio dela, foram incluídas mais 14 PICS para compor o quadro de oferta no Sistema Único de Saúde (SUS), sendo elas: Arteterapia, Ayurveda, Biodança, Dança Circular, Meditação, Musicoterapia, Naturopatia, Osteopatia, Quiropraxia, Reflexoterapia, Reiki, Shantala, Terapia Comunitária Integrativa e Yoga (MENDES, et al., 2019).

As PICS buscam acolher o sujeito, valorizando sua singularidade e subjetividade, através de uma maneira autoeducativa que objetiva o desenvolvimento do potencial humano, buscando incentivo ao autoconhecimento, autocuidado e autotransformação. Essa prática possui certos benefícios como baixo custo e eficácia (SPEZZIA; SPEZZIA, 2018).

O Reiki é uma terapia holística fundamentada no conceito de energia vital (Rei significa universal e Ki, força vital). Idealizada por Mikao Usui no início do século 20, o Reiki consiste em estimular os canais de energia do paciente por meio da imposição das mãos do praticante em diferentes posições sobre ou suavemente acima do corpo do paciente. É uma técnica utilizada para ajustar os desequilíbrios de energia vital do paciente (BEULKE et al., 2019).

Os profissionais que trabalham com as Práticas Integrativas e Complementares (PICS), instigam o sujeito a descobrir seu bem-estar e equilíbrio, uma vez que compreendem que o corpo, assim como a natureza, tem habilidade própria de buscar o equilíbrio do bemestar e diante disso melhorar a qualidade de vida (FREITAG et al., 2014).

\section{OBJETIVO}

Relatar experiência de acadêmicas de enfermagem enquanto bolsistas voluntárias do 


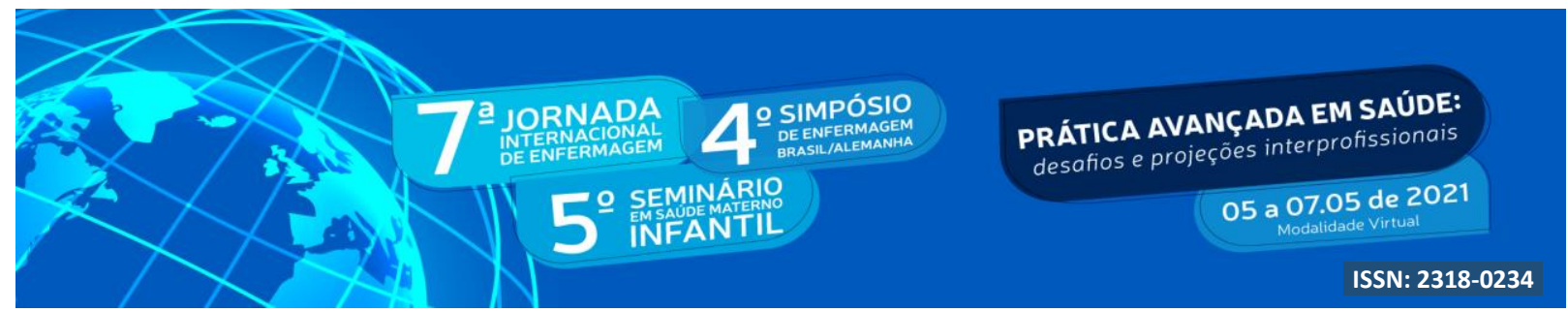

Laboratório de Práticas Integrativas e Complementares em Saúde- LAPICS, na atuação de roda de conversa online sobre Reiki durante a pandemia COVID-19.

\section{METODOLOGIA}

Trata-se de um relato de experiência de acadêmicas de enfermagem enquanto bolsistas voluntárias em um Projeto de Ação Social intitulado: Laboratório de Práticas Integrativas e Complementares em Saúde- LAPICS, em uma universidade na região centro oeste do Rio Grande do Sul.

Devido à pandemia do COVID-19, o projeto foi impossibilitado de acontecer presencialmente. Desta forma, as atividades ocorreram de forma remota, via plataforma Google Meet, no período de setembro a dezembro de 2019. Os participantes foram acadêmicos de diversos cursos de graduação e pós-graduação, mestrandos e doutorandos, servidores da universidade e, ainda, a comunidade em geral, tanto do Rio Grande do Sul, quanto de outros estados.

Ocorreram cinco encontros online, com cinco temáticas diferentes ministradas por diversos profissionais de cada área. Além de atividades teóricas, algumas PICS foram realizadas na prática, mesmo que de forma online. Pretende-se relatar o encontro que foi abordado a terapia Reiki.

\section{RESULTADOS E DISCUSSÃO}

O Reiki é uma terapia holística que trata do biocampo. Cujo objetivo é reestabelecer o equilíbrio físico, psicológico e emocional, mostrando ações relevantes no cuidado em saúde, principalmente acerca dos aspectos de ansiedade, sinais depressivos, estresse, sistema imunitário, dor e níveis de pressão arterial sistólica (BATISTA; BORGES, 2020).

O encontro com a temática Reiki foi o segundo a ser realizado via google meet, ocorreu no dia 30 de setembro de 2020, contou-se com a participação de uma Terapeuta Holística, Mestre em Reiki e Thetahealer. Ao se empregar o reiki, o objetivo é permitir autocura por intermédio do reequilíbrio enérgico do corpo físico e mental debilitado, uma vez 


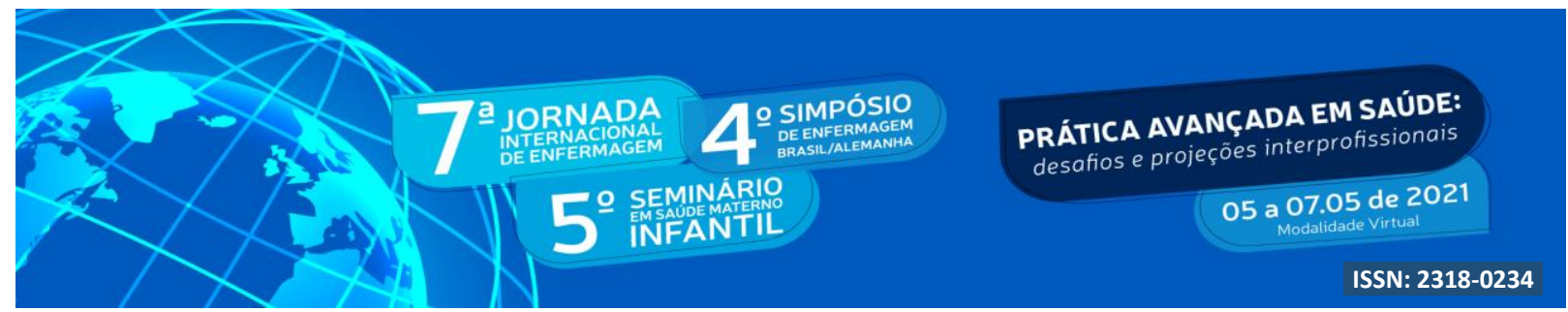

que, para a medicina oriental, um corpo equilibrado energeticamente é capaz de atingir mecanismos em prol do autocuidado e a manutenção do bem-estar (OLIVEIRA et al. 2020).

Durante este encontro, contou-se com a participação de cerca de 40 pessoas incluindo acadêmicos dos cursos de Enfermagem, Farmácia, Nutrição, Tecnologia em Alimentos, Jornalismo, Educação Física e Gestão Pública, bem como profissionais da Enfermagem e Tecnólogo em Alimentos, além da comunidade em geral, de diversas cidades do estado.

Cabe destacar que além da atividade teórica ministrada pela convidada, neste encontro foi possível desfrutar e receber o envio de REIKI à distância, para que fosse possível receber esta energia os participantes só necessitaram escrever seu nome completo no chat do encontro, foi solicitado para que estivessem em um ambiente tranquilo e se colocando em uma posição confortável. A terapeuta também utilizou da musicoterapia por meio de um mantra.

As tecnologias permitem a troca do conhecimento e o compartilhamento de informações a quem encontre-se conectado à web pode ter acesso às informações com apenas um clique. As inovações tecnológicas e a internet modificam a forma de transmitir novos conhecimentos (CARNEIRO; GARCIA \& BARBOSA, 2020).

\section{CONCLUSÃO}

O estudo mostrou que por meio do uso das Tecnologias Digitais de Informação e Comunicação foi possível obter resultados satisfatórios, no que se diz respeito a participação de diversos indivíduos de áreas multiprofissionais e pertencentes a cidades e estados distinstos. Da mesma forma observou-se a busca por essas pessoas na compreensão das Práticas Integrativas e Complementares em Saúde, seus benefícios e diversas possibilidades de melhorar sua qualidade de vida sob uma visão holística que proporciona um cuidado de qualidade e integral.

Diante dos resultados positivos obtidos após a roda de conversa, é possível afirmar que o REIKI, contribui para que os pensamentos positivos sejam potencializados e canalizados proporcionando equilíbrio e por fim aumentando os efeitos saudáveis em sua vitalidade. 


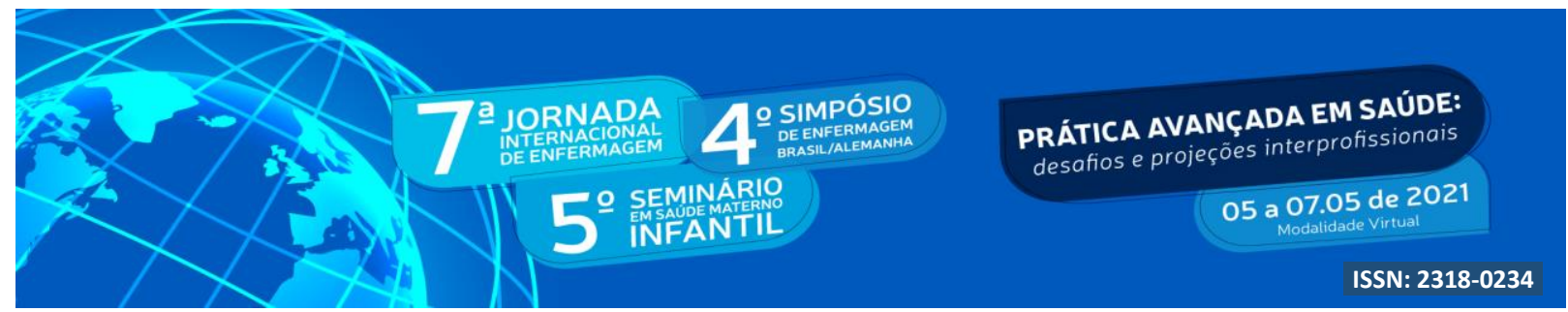

Ainda resalta-se que durante o cenário atual pandêmico se está trabalhando de uma forma que requer o uso das tecnologias, das quais muitas vezes não se chega a um produto palpável, porém da mesma forma se produz saúde. No decorrer do projeto, as bolsistas obtiveram uma maior compreensão acerca das PICS, pois até o momento só tinham conhecimento teórico. Também puderam trazer à tona o pensamento crítico reflexivo e impulsionar a sua prática a partir da criatividade, dinamicidade e relações interpessoais.

\section{REFERÊNCIAS}

BATISTA, K. de M.; BORGES, L. M. Terapia Reiki como estratégia de intervenção na dor e no estresse em estudantes de enfermagem. Revisa, v. 9, n. 1, p. 109-117, 2020.

BEULKE, S. L. et al. Reiki no alívio de sinais e sintomas biopsicoemocionais relacionados à quimioterapia. Cogitare enferm., v. 24, p. 1-10, 2019.

BRASIL. Ministério da Saúde. Gabinete do Ministro. Portaria nº 971, de 03 de maio de 2006.

FREITAG, V. L. et al. Benefícios do reiki em população idosa com dor crônica. Texto Contexto Enferm, v. 23, n. 4, p. 1032-40, Florianópolis, Out-Dez, 2014.

OLIVEIRA, P. M. et al. Reiki e meditação mindfullness no manejo do paciente com dores crônicas: uma revisão de literatura. Braz. J. Hea. Rev., Curitiba, v. 3, n. 1, p. 1155-1167 jan./feb. 2020.

SPEZZIA, S.; SPEZZIA, S. O uso do reiki na assistência à saúde e no sistema único de saúde. R. Saúde Públ., Paraná, v. 1, n. 1, p. 108-115, Jul 2018.

MENDES, D. S. et al. Benefícios das práticas integrativas e complementares no cuidado de enfermagem. Journal Health NPEPS. v. 4, n.1, p. 302-318, 2019.

CARNEIRO A. C., GARCIA, L. G., \& BARBOSA, G. V. Uma revisão sobre aprendizagem colaborativa mediada por tecnologias. Revista Desafios, v. 7, n. 2, p. 52-62, 2020. 